\title{
10 A future-oriented evaluation and development model for Responsible Research and Innovation
}

\author{
Mika Nieminen and Veikko Ikonen
}

\subsection{Introduction}

Recently there has been considerable discussion about Responsible Research and Innovation (RRI) (e.g. von Schomberg, 2011; Owen, Bessant, \& Heintz, 2013; Gianni, 2016; Yaghmaei, 2018) as a continuation of the various debates on risk anticipation and the ethics of technological development (e.g. technology assessment and ethical, legal and social aspects studies). Consequently, a number of attempts have been made to operationalize the concept of RRI, for instance in the design of research projects and in the implementation of innovations. Most notably, in a number of European Union (EU) projects specific "toolboxes" for applying RRI have been developed (e.g. RRI tools ${ }^{1}$ ), ideas of RRI governance have been studied (e.g. EGAIS $^{2}$ and ResAgora ${ }^{3}$ ), and evaluation frameworks for RRI have been created (e.g. MoRRI ${ }^{4}$ and Satori ${ }^{5}$ ).

However, such RRI evaluation frameworks typically have a relatively general focus on, for instance, ethics assessment practices, with less attention paid to contextual embeddedness and organizational factors. In addition, it seems that there is hardly any explicit connection to evaluation theory. In the following discussion, we aim to contribute to RRI evaluation by paying specific attention to these elements. The discussion functions as a starting point for our developed RRI evaluation model, providing it with a more solid and contextualized basis.

Our general starting point is that the development of responsibility in research and innovation depends on the complex interactions between various actors and on organizational dimensions and their dynamic codevelopment with the organization's external environment. Due to this complexity, organizational change is not a fully manageable and controllable process in the organization, contrary to still relatively commonly held beliefs (e.g. Tsoukas \& Chia, 2002). This view can also be called systemic, including the idea that various dimensions of an organization, such as political, cultural and structural processes, are intimately intertwined and affect each other directly and indirectly via various feedback loops, forming a complex system (e.g. Cao, Clarke \& Lehaney, 2003). Concurrently, societies 
have also become profoundly complex and interconnected due to changing institutional structures, globalization, rapidly developing technologies and the intertwining of human-made and natural systems (e.g. Urry, 2005; Helbing, 2013).

Recently, this complexity and the systemic nature of our organizations and societies have gained the attention of a growing number of evaluation experts and scholars (e.g. Forss, Marra, \& Schwartz, 2011; Williams \& Hummelbrunner, 2011; Mowles, 2014; Nieminen \& Hyytinen, 2015). The central idea is that input-output-outcome linear thinking, which is manifest in many traditional approaches to evaluation (e.g. Kellogg Foundation, 2004; Wholey, Hatry, \& Newcomer, 2010), does not match well with the complexity of processes and the multiple relationships between actors. Therefore, many system thinking-based approaches emphasize participative, developmental and process-based evaluation approaches that better capture this complexity (e.g. Patton, 2011; Williams \& Hummelbrunner, 2011), the core idea being the development of something concrete (instead of summative, outcome-oriented approaches) and active stakeholder and citizen engagement in the process. At the same time, attention has been paid to the necessity of including anticipatory elements in evaluation studies: fast societal development may make ex post evaluations less useful, as recommendations based on past operations may turn out to be outdated, especially in rapidly developing societal and industrial sectors (e.g. Nieminen \& Hyytinen, 2015; Hyytinen, 2017). Participatory approaches, anticipation of future impacts and reflexivity are also the basic dimensions of the concept of responsible innovation (Owen et al., 2013; Stilgoe, Owen, \& Macnaghten, 2013), although the emphasis has been on the assessment of social acceptability and desirability in the context of potential risks.

Using these approaches as a starting point, in this chapter we describe a concrete evaluation approach for integrating RRI into the development principles and procedures of innovation activity. The model was developed in 2018 for an urban development project called 6 Aika $^{6}$ (a joint development and strategy project of Finland's six largest cities) with the specific aim of developing innovation and business platforms. The developers of the 6Aika project wanted to integrate RRI thinking into the platform development by extending the range of societal impacts beyond economic impacts towards wider societal, cultural and environmental impacts. The model was developed in close collaboration with the developers of an evaluation framework for the open innovation platforms, and further discussed in an international workshop of innovation platform developers participating in the MARIE (MAinstreaming Responsible Innovation in European S3) project. The model will be utilized in future Six City projects and in the development of open innovation platforms. The aim of this chapter is thus to introduce a practical, yet theoretically argued, ex ante evaluation approach to embed responsibility thinking into innovation platforms. 
The chapter is structured as follows. In Subsection 10.2.1, we introduce the basic theoretical assumptions behind our approach. In Subsection 10.2.2 we then briefly review the evaluation approaches that take systemic complexity as their starting point and compare these views with the presented RRI evaluation approaches. Based on this, we argue for a need for a systemic and future-oriented evaluation approach for developing and evaluating responsibility-related practices in organizations. In Section 10.3 we introduce our evaluation model, and in the final section we summarize our arguments.

\subsection{Theoretical background}

\subsubsection{Complexity and heterogeneity}

A major driver of increasing complexity during the last few decades has been globalization. Although economic globalization began as far back in history as the Middle Ages, recent developments in ICT have made global networks more intensive, intensified economic globalization and coupled people, their organizations and economic structures more tightly with each other across the world (e.g. Castells, 1996; Friedman, 2005). Simultaneously, technological developments have taken place at an increased pace (e.g. Kurzweil, 1999), created huge and complex technological systems (Hughes, 1983) and have become profoundly intertwined with social, environmental and economic developments (e.g. Freeman \& Louca, 2002). Business is taking place in global "value chains" and "ecosystems", to use two concepts that describe the complex interdependencies of various business-related actors (e.g. Moore, 1996; Autio \& Thomas, 2013). It has also been shown that changes in one part of the global system can crucially affect the performance of other systems and even produce crucial systemic risks. For example, as global energy and food systems, communication systems and production and natural systems become increasingly dependent on each other, the vulnerability of the whole is also increased (Helbing, 2013).

Wide systemic interconnectedness increases complexity, which in turn increases volatility and unanticipated changes across systems as different parts are indirectly coupled with each other (Holland, 1995; Lawrence, 2013). This further highlights the challenge of ambiguity: there may be various legitimate starting points and perspectives for interpreting and evaluating on-going developments, from techno-economic concerns to interpersonal relationships and social and ethical concerns (cf. Rittel \& Webber, 1973). Due to the multi-dimensionality of socio-economic and environmental challenges, it is difficult to make decisions based on only certain views or interests. Solving such challenges, whether on a global or national scale (e.g. climate change, migration or unemployment) or on an organizational level (e.g. strategic decisions on product and service development and provision) 
requires the engagement of various actors in the problem-solving process. It is also possible that there is no definite solution to these challenges - as situations and actors change we therefore need to constantly create new, specific solutions that fit the situation (Eoyang \& Holladay, 2013).

The development and implementation of successful innovations have thus become an increasingly complex endeavour. Innovations are a result of the interaction of various actors and contextual factors in an innovation environment, including businesses, knowledge-producing organizations and the wider institutional context in society (e.g. Damanpour, 1996; Geels \& Schot, 2007; Borras \& Edler, 2014). These actors and their various relationships (e.g. collaboration, transactions, competition, steering) form a system that influences the possibilities for innovation activity (e.g. Smith, 2000; Edquist, 2005). While the concept of "innovation system" emphasizes the heterogeneity of actors and the systemic constellations they may form, recently the concept of innovation ecosystem has also emphasized the mutual dependencies of various innovation- and business-related actors from companies to universities and research institutes (e.g. Moore, 1996; Autio \& Thomas, 2013).

Interconnectedness also becomes visible in so-called systemic innovations. A systemic innovation is an innovation that is dependent on changes in other technologies or social subsystems (such as markets or regulation) (Teece, 1988). Innovation may also emerge through a combination of various technologies, services or social innovations, which becomes possible only when various actors and system dimensions are in interaction with each other. We can take the mobile phone as an example. Their success has been dependent on the development and combination of various technologies (e.g. signal processing, battery technology) and services (e.g. applications, music and news services, social media) which together have made possible radical and systemic changes in communication and social activity. Such innovations are "systemic" by nature in the sense that their implementation requires changes in the existing technological system and markets as well as in the institutional context (e.g. regulation) and in organizations (e.g. how work is organized when the new technology is implemented) (e.g. Geels \& Schot, 2007; Hyytinen 2017). Therefore, the implementation of an innovation may require diverse communication, shared target setting and joint activities. This also implies the idea of open innovation (Chesbrough, Vanhaverbeke, $\&$ West, 2006; cf. von Hippel, 1988) and co-creation to increase the social effectiveness and business impact of innovation.

Co-creation relies especially on the collective creativity of all stakeholders and end-users in innovation processes (Prahalad \& Ramaswamy, 2000; Sanders \& Stappers, 2008). User participation is especially useful in the early stages of innovation due to the high level of uncertainty and low formalization (Alam, 2006). Whereas in traditional human-centred design only a small number of users are involved in design activities, co-creation suggests wider stakeholder and citizen inclusion, emphasizing the creative 


\section{Mika Nieminen and Veikko Ikonen}

nature of participation, seeking new solutions, concepts and ideas, as well as equal and open interaction between different actors (Ainasoja et al., 2012; Kaasinen et al., 2010).

The need to open up innovation processes to various stakeholders and citizens is further emphasized by the normative and relative nature of social impacts. For instance, the social, environmental and economic impacts of an innovation (e.g. economic and environmental impacts of mining or transportation-related innovations) may be in contradiction and need to be negotiated. Responding to them necessitates opening up innovation processes and connecting them to solving problems that people consider important (e.g. Schot \& Steinmuller, 2018). Complexity also emphasizes the need for careful anticipation, as there may be systemic impacts that are otherwise difficult to foresee. Engagement of stakeholders increases, in turn, possibilities for reflection on potential future impacts from various perspectives (cf. Owen et al., 2013).

\subsubsection{Towards systems thinking in evaluation}

As discussed in the previous section, our societies and organizations have become increasingly complex and rapidly changing (e.g. Urry, 2005) and traditional evaluation approaches no longer function well for two main reasons. Firstly, they tend to over-simplify the complexity of impact paths. Typically, a range of factors and actors contribute directly and indirectly to observed results or impacts, yet this has been taken insufficiently into account. Secondly, many evaluations are backward-looking (ex post evaluation), whereas social and economic changes take place rapidly and instead necessitate forward-looking and anticipatory approaches (Nieminen \& Hyytinen, 2015; Hyytinen, 2017).

Traditional evaluations are also predominantly based on rather straightforward linear, causal thinking. It is assumed that impacts are produced in a linear manner following the chain inputs-process-outputs-impacts. Evaluations normally also include contextual factors that may affect the delivery of the planned outcomes and impacts. The activity then needs to be adapted to take into account these contextual factors (e.g. Dyehouse, Bennett, Harbor, Childress, \& Dark, 2009; Gertler, Martinez, Premand, Rawlings, \& Vermeersch, 2011). Mainstream evaluations seem to roughly follow this model in one way or another (Patton, 2011). There are also various sophisticated variations on this theme including, for instance, "contribution analysis". This puts forward the idea that the outcomes of an activity may be attributed also to factors other than the activity being evaluated (which is usually some kind of intervention, programme, etc.). The basic idea is to ask whether "in light of the multiple factors influencing a result, has the intervention made a noticeable contribution to an observed result and in what way" (Mayne, 2012, p. 273). Contribution analysis usually also postulates a theory of change that includes the assumed causal linkages yielding the sought-after targets. 
Currently, there are various attempts to evaluate the advancement of RRI. In the following, some recent EU-funded RRI projects representing the state of the art in the field are used as examples.

Some projects explicitly follow the linear model, albeit recognizing its problems. For instance, the researchers of an EU-funded project (ended in 2018) Monitoring the Evolution and Benefits of Responsible Research and Innovation (MoRRI) explicitly state in the final report that "the indicators developed to monitor the emerging patterns of RRI at Member State level (Section 2) were based on a relatively conventional intervention logic: inputs $\rightarrow$ outputs $\rightarrow$ outcomes $\rightarrow$ impacts" (MoRRI, 2018, p. 11). While this concerns macro-level impact monitoring, the researchers also collected survey and case-based data on the impacts of RRI and moved beyond straightforward linear thinking towards contribution analysis. They also recognize the problems of attributing observed impacts to RRI:

The problem of attribution of very general effects to RRI processes and outcomes is a significant challenge for developing a monitoring system for RRI benefits. Lengthy timelags can occur between observed changes in the R\&I [research and innovation] system, which might be monitored through indicators of RRI outcomes, and flow-on or emergent benefits to society at large.... This is [the] measurement theory challenge in the field of indicator development generally.

(ibid., 22)

While MoRRI can be seen as representing the so-called summative evaluation approaches, another recent EU-funded RRI project (ended in 2017), Stakeholders Acting Together on the Ethical Impact Assessment of Research and Innovation (SATORI), represents a different approach to evaluation by trying to create a formative procedure or framework for ethical assessment. In essence, the framework is an ex ante evaluation approach that also utilizes foresight studies to describe the ethical impacts of research and innovation (Reijers, Brey, Jansen, Rodrigues, Koivisto, \& Tuominen, 2018). The proposed framework also suggests wide engagement of stakeholders in the evaluation. The actual framework consists of six consecutive steps, each of which includes various actions, and each starting with an analysis of the need for ethical assessment and ending with a review process aimed at giving feedback to iteratively develop the process (ibid.). The SATORI approach aims at developing standardized practices in organizations performing and funding research and, in doing so, assumes rather direct causal linkages between improved ethical performance in an organization and its social impacts.

In the EU project Responsible Industry (ended in 2017), an evaluation model was created to foster RRI practices in firms. The so-called RRI maturity model was developed in collaboration with five companies with 


\section{Mika Nieminen and Veikko Ikonen}

the aim of helping firms to understand and reflect on their current practices and benchmark practices in the industry. ${ }^{7}$ In essence, the maturity model identifies categories and components of RRI that could serve as building blocks for further development of RRI. The RRI maturity model:

is a tool that generally overviews and provides an empirically tested basis for drawing practical conclusions that can inform organizational practice. Its theoretical contribution to the discussion of RRI is thus twofold: It firstly allows for a more comprehensive view of RRI that combines existing accounts and it secondly allows moving beyond the one-dimensional view of RRI to a multi-dimensional account that paves the way for practical interventions.

(Stahl, Obach, Yaghmaei, Ikonen, Chatfield, \& Brem, 2017)

Here "more comprehensive view" is understood to refer to the fact that, as RRI was originally developed for the EU research and innovation context, changing the context to company research and innovation calls for a different terminology, approach and deployment. For example, instead of open science, the concept of open innovation can be more relevant to companies while at the same time they may have a need for intellectual property rights and knowledge protection.

This kind of attempt to develop practices by using an inclusive and collaborative evaluation approach comes close to the so-called developmental evaluation approach. Developmental evaluation aims at developing an organizational practice or an innovation. One of the developers of the approach, Michael Patton (2011), considers it as a response especially to the challenges emerging from societal complexity. Thus, according to Patton (ibid. 7), "Developmental evaluation ... is an approach to evaluation especially appropriate for situations of high uncertainty where what may and does emerge is relatively unpredictable and uncontrollable". Developmental evaluation does not rely on any specific methodology, but can use various methods to support development. While developmental evaluation does also recognize causality, for it, causality is the "patterns" embedded in "complex systems dynamics and interdependencies" (ibid., p. 24).

Patton's approach reflects the growing dissatisfaction with linear approaches during recent years and increasing interest towards systems thinking in evaluation - even though the linear approaches still form the mainstream (e.g. Cabrera, Colosi, \& Lobdell, 2008; Dyehouse et al., 2009). What is common to these various approaches is that they are trying to pay attention to the interrelationships among actors, between the whole and its parts, and between the action and its context (Cabrera et al., 2008; Nieminen \& Hyytinen, 2015). The roots of this system thinking can be found in research fields like general systems theory, system dynamics, and complexity science. In practice, the system approach has been applied as an 
analytical perspective and as a multi-method approach (Williams \& Imam, 2006; Dyehouse et al., 2009; Nieminen \& Hyytinen, 2015).

Hyytinen (2017) has suggested an evaluation approach based on three perspectives: "futures view, systems view and multi-actor view". A futures view is linked to the observation that, while our environment is increasingly complex, it is also changing rapidly. Recommendations based on traditional ex post evaluations can easily prove out of date. Moreover, innovation is always future-oriented, as the impacts of innovations take place in the future. A systems view emphasizes the need to take into account complex direct and indirect interlinkages between different factors and actors in the activities producing social impacts, and emphasizes that this should be reflected in the approach to and methodologies for evaluation. A multi-actor view pays specific attention to various perspectives, interests and motivational factors "that make innovations happen, spread and gain foothold". As a methodological solution Hyytinen suggests a combination of evaluation, foresight, system dynamic modelling and societal embedding. In this ensemble "evaluation provides information on the past and current state of the system, its structures, operations and historical development" and foresight "yields information about future transformations in the system and endorses the setting of long-term targets". Furthermore, system dynamic modelling provides "analysis of interdependencies and feedback loops among the actors and their environment", and societal embedding "an approach to initiate the dialogue among various stakeholders and key actors who set conditions for social development and for diffusion of social or technological innovations" (Nieminen \& Hyytinen, 2015, pp. 453-454).

Based on the ideas of Hyytinen (2017) and of Nieminen and Hyytinen (2015), in the following we suggest a practical organizational approach for future-oriented and multi-perspective evaluation of responsibility. The general aim of the model is to be "developmental" in the sense discussed above, not summative (i.e. the focus is not on outcomes but on processes and the development of actions).

The model was originally developed for the 6Aika innovation platforms. ${ }^{8}$ 6Aika is a joint strategy for sustainable urban development of the six largest cities in Finland that aims to tackle the challenges of urbanization and to create new business, know-how and jobs in Finland. This Six City strategy has three large-scale spearhead projects: Open Data and Interfaces, Open Participation and Customership and Open Innovation Platforms. The projects embody the smart city model defined in the strategy: customercantered co-creation, opening and utilizing data and developing services in real urban environments. The cities have opened and are opening up real and virtual spaces and turning them into innovation platforms: schools, shopping centres, hospitals, nursing homes, streets and neighbourhoods as innovation platforms and co-creation facilities where new products and services are developed and tested. The aim of the model that we planned for 
6Aika was to include responsibility-related elements as important design and evaluation criteria for platform design.

\subsection{Future-oriented evaluation and development model for Responsible Research and Innovation}

Although various slightly different definitions of RRI have been proposed (e.g. Sutcliffe, 2011; von Schomberg, 2011; Owen et al., 2013), they each share a number of common RRI characteristics, such as a focus on social challenges, engagement of stakeholders, opening up of research and innovation to society and risk avoidance (Gurzawska, Mäkinen, \& Brey, 2017; Smallman, 2018). For instance, Owen and his colleagues (2013, p. 38) suggest four basic dimensions of responsible innovation which include the above-mentioned elements. Anticipation is a necessary part of the analysis of the social, economic and environmental impacts of innovation activity in a rapidly changing society. Reflexivity is an essential part of every actor's operations. Each actor should consider their own underlying motivations and purposes for participating in the innovation activity and ponder them openly together with the other actors. Inclusiveness brings into the common discussion various stakeholder and citizen interests, values and perspectives. Finally, the process needs to be responsive, leading to learning and changing of target-setting and operative practices. These basic principles of responsible innovation also fit well with our understanding of the increasingly complex and systemic social context, in which research and innovation activities are embedded. Here, we use the definition suggested by Stilgoe and colleagues (2013, p. 1570), according to which RRI aims at "taking care of the future through collective stewardship of science and innovation in the present". The definition is broad enough to be used in various kinds of innovationrelated activities and captures well the general (normative) idea of RRI.

Figure 10.1 depicts the basic ideas of our model. As explained earlier, the model incorporates the ideas of a future-oriented, systemic and multi-actor approach, as well as developmental evaluation. The principles of responsibility are intertwined in the step-wise process from the very beginning and define the targets of successive actions. The dominating character of the process is co-creation, which essentially defines the values and operational goals of the innovation activity. At best, the process forms a loop of continuous learning in which participating organizations and persons learn from each other during the evaluation process and reflexively change their activity. Evaluation is not used only for the anticipation of potential impacts, but also for following the results and impacts of the development process. The evaluation of responsibility should be an integral part of "business-as-usual" everyday planning and management in an organization (cf. Reijers at al., 2018) and our model may help by suggesting practical steps towards achieving this. The evaluation and learning loop should ideally be embedded also in the innovation process, which is depicted in the figure as different phases by adapting Kline and Rosenberg's (1986) classical analysis of the innovation process in firms. 


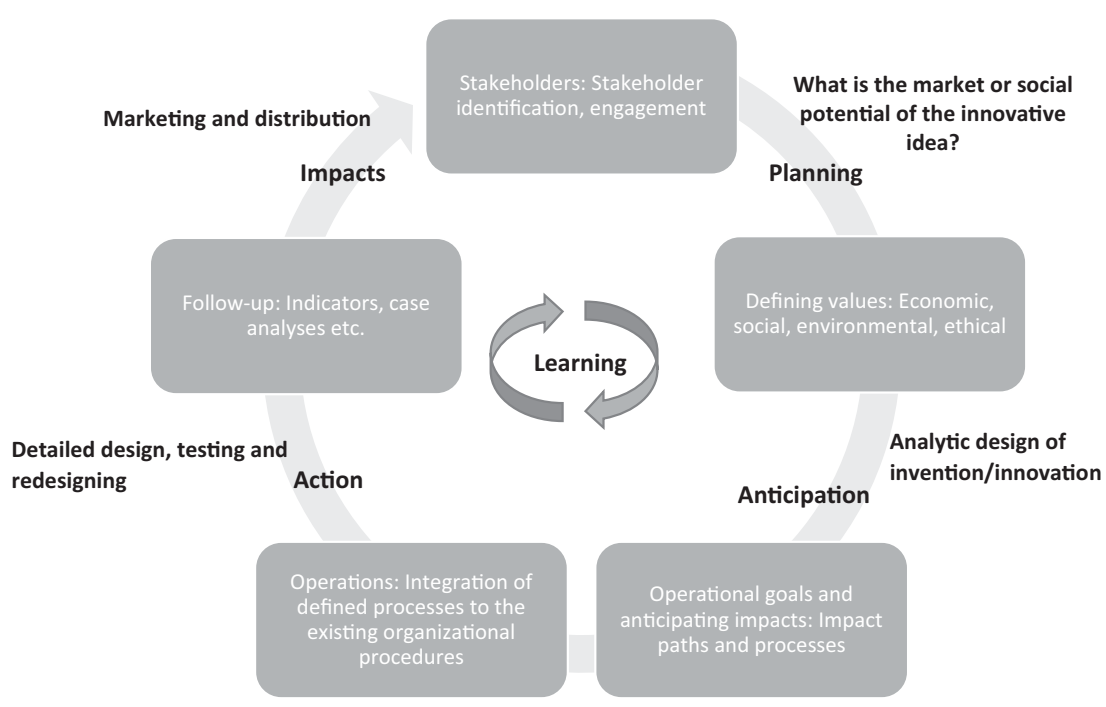

Figure 10.1 Future-oriented Responsible Research and Innovation (RRI) evaluation.

Besides defining the joint targets and shared values for the innovation activity, the goal of the process is also that the participating organizations and people change their own behaviour so that the joint targets are possible to achieve. Broad societal goals or socio-technical innovations are especially systemic by nature and various societal dimensions, organizations and people affect the realization of these targets (e.g. Geels \& Schot, 2007). Achieving these goals or implementing innovations necessitates the creation of shared visions, collaboration between and networks of many organizations and people, learning and operational adjustments (e.g. Rotmans \& Loorbach, 2009). For instance, utilizing ICT in health care is not only about implementing new technological instruments, but necessitates wide changes in the health care organization, including, for example, work practices, management and customer relationships. In addition, changes are needed in public policy as well as in customers' attitudes towards new services (e.g. Kivisaari, Väyrynen, \& Saranummi, 2004). This emphasizes the developmental evaluation approach with its idea of evaluation as an inclusive process in which participants codevelop new socio-technical innovations and ways to implement them.

\subsubsection{Stakeholder identification and engagement}

In a complex social environment it is important that all relevant stakeholder groups are involved from the very beginning of the process. These participate in defining the targets of innovation activity and related elements of responsibility and values as well as in anticipating the impacts and potential risks. The process connects the values of stakeholder groups to the innovation 
process, brings out the positive and negative aspects of the innovation activity and increases the acceptability and desirability of innovations (cf. Leikas, 2009; Saariluoma, Cañas, \& Leikas, 2016). The stakeholder groups should also be involved in ex post or mid-term evaluation, in which it is assessed whether the defined targets have been reached and, if not, why they have not been achieved. Engagement in these discussions should be a mutual learning experience for all of the participants.

Deciding who is and who is not a stakeholder is, however, not an easy task, which is reflected, for example, in the different stakeholder definitions and analytical frameworks for stakeholder analysis. For instance, a definition by Freeman (1984, p. 46) states that a stakeholder is "any group or individual who can affect or is affected by the achievement of the organization's objectives". This definition is relatively broad compared, for instance, with the definition suggested by Eden and Ackermann (1998, p. 117), who consider stakeholders to be "people or small groups with the power to respond to, negotiate with, and change the strategic future of the organization". ${ }^{9}$ For the purposes of RRI and social and environmental responsibility, even the definition by Freeman may be too narrow. When considering the future impacts and consequences of an innovation, we should also take into account those potentially affected by the organization or the actions of groups of organizations. These additions would take into account the need for systematic anticipation of the long-term and less obvious impacts of the innovation, as well as the fact that the innovation does not take place in isolation. Organizations are often dependent on other organizations in their innovation activity (e.g. Adner, 2012), which means that organizations involved in collaborative innovation activity should view RRI also as a collective action with other involved firms. Impacts of the innovation may be also global, which makes the definition of "stakeholder" even more challenging. This fuzziness of the concept also emphasizes the fact that from the system theoretical point of view "stakeholder" may be a too restrictive concept, as it emphasizes a central, definable organization and its operational environment. In a systemic and complex environment even the concept of organization may become blurred, and the relationships with the environment and its various actors are difficult to define. While this question remains unanswered here, we take a practical orientation to this dilemma: a systematic approach to thinking about "stakeholders" is better than ad hoc attempts to identify potential groups of people or actors.

Systematic stakeholder-mapping techniques and analysis that support the identification of stakeholders, analysis of their interests and engagement in the process help. There are various variants of stakeholder analysis (e.g. Mitchell, Agle, \& Wood, 1997; Mayers \& Vermuelen, 2005) and these can be used for different purposes, from analysing stakeholder power resources to inequalities. Reed et al. (2009) have suggested that there are three main variants of stakeholder analysis, including the descriptive (empirically describes stakeholders and their characteristics), normative 
(aiming to engage stakeholders to reach a shared understanding and legitimization of action) and instrumental approach (aiming to understand how organizations can identify and manage stakeholders to reach their targets). These approaches, in turn, may use various methods to identify stakeholders, categorize them and investigate stakeholder relations. We are unable to discuss these methods here in detail due to length restrictions, but in the following we provide some examples of useful methods. For identifying stakeholders: semi-structured interviews and snowball sampling (initially identified stakeholders identify new stakeholder categories and contacts; these are then asked to identify again more stakeholders and so forth); for stakeholder categorization: interest-influence matrices (stakeholders are placed in a matrix according to their interest and influence; this can be done by stakeholders themselves, e.g. in a workshop) and stakeholderled stakeholder categorizations (as in the previous method); and for stakeholder relationships analysis: actor-linkage matrices (analysis of linkages in a two-dimensional matrix) and social network analysis (structured analysis of relationships) (ibid.).

In the context of RRI, stakeholder analysis should function as part of a systematic attempt towards more open innovation activity, sharing of information and increasing transparency of the innovation and various actors' roles in the process. Systematic and successful stakeholder analysis may help to identify the relevant actors, ponder their potential roles and integrate them as part of the innovation process or development platform. Unsuccessful identification and engagement of stakeholders may cause challenges in the implementation of innovation (its acceptance and desirability). An example might be the inclusion of citizens in the platform development. The perhaps seemingly simple question of stakeholder identification can turn out to be rather complex when considering potential social groups (e.g. age, gender, religious and ethnic identity), their internal diversity (including e.g. different political opinions) and suitable organizations, associations or persons to represent these groups. In such cases, stakeholder analysis can help to identify relevant and important actors and bring to the fore the diversity of values of different stakeholder groups.

\subsubsection{Defining values, operational goals and impacts}

As we know, innovation processes are always contextual (e.g. Ortt $\&$ van der Duin, 2008), which refers to the fact that implementation challenges and relevant questions vary depending on, for example, the organization, societal sector or industrial branch, the technology or service and the use of the innovation. Following from this, social and ethical questions that are important to biotechnology may differ from those that are important to ICT (cf. Luppicini, 2010). This contextuality emphasizes the importance of the engagement of relevant and concerned parties and their values in the innovation process. Values define the social acceptance and desirability of 
the innovation. In this context, values can be defined "as something that a person or a group of people consider important in life" (Friedman, Kahn, \& Borning, 2006, p. 349, as cited in Simon, 2016, p. 221). This kind of valuesensitivity should be an integral part of the responsible design of technologies, as it enhances successful and sustainable uptake of innovation - even though it means both critical analysis of the values inscribed in the technology development as well as intentional integration of the desired values into the technology development (Simon, 2016).

Desirability aspects may be especially challenging for innovation actors who are accustomed to operating based on acceptability, which is often understood narrowly to cover, for example, technological usability and improvement aspects, instead of asking whether the innovation or technology is actually needed and serves real existing needs in people's lives (Leikas, 2009; Saariluoma et al., 2016).

This value sensitivity can be easily criticized for being overly relativistic. Because values are anchored in people's life experiences, they are all equally valuable and negotiable. However, this does not hold true for generally accepted values and norms, such as human rights and existing legislation. There are certain values that can be considered generally important for society even though contextuality and desirability may relativize their value and importance. An example of integrating these two perspectives is provided by a recent EU-funded project "Responsible Industry" (2017), the values and core questions of which were defined with a view to advancing the implementation of RRI. The suggested general values included individuals' rights and liberties, personal safety and health, autonomy, quality of life, integration and dignity, and justice. These general values were then integrated into the innovation process by reflecting them on to the more relative values of societal and ethical impacts.

Values are also tightly anchored to the future promises and visions provided by innovations and new technologies. Innovations always have future consequences for us, which should raise the question of whether we value those consequences, whether they are in accordance with our values. It is equally important to anticipate the potential risks and indirect and unintended impacts of innovation activity. These potential negative impacts also have to be compared with and weighed against the positive impacts. How big may acceptable negative impacts be compared to positive ones? As there is no clear-cut answer to this question, it is sensible to discuss it with stakeholders and citizens. Discussion helps to piece together various situational values, ethical questions and responsibilities. Discussion may also help to find new, more acceptable solutions and create compromises and shared visions of desirable or acceptable futures.

These goals can be supported by systematic foresight methods (e.g. Georghiou, Cassingena Harper, Keenan, Miles, \& Popper, 2008). At its best, the foresight process integrates different values and interests into the innovation process by asking: what kind of innovation do we want and 
accept? In addition, it is possible to create alternative scenarios to describe possible futures, and define impact and vision paths or roadmaps to assist goal attainment. A roadmap or an impact path can also include various concrete mid-term targets and operations that help to achieve the shared vision (Auvinen, Ruutu, Tuominen, Ahlqvist, \& Oksanen, 2014). In addition, various well-known approaches are available for assessing the impacts of technology development that support the objectives of making various values visible, producing needed information and reaching consensus. These include, for instance, technology assessment and its various variants (Schot \& Rip, 1997), combination of risk analysis and technology assessment (van Wezel et al., 2018), ethical, legal and social aspects assessment in life sciences and various impact assessment approaches from environmental to health impact assessments (João, Vanclay, \& den Broeder, 2011).

\subsubsection{Integration into the organization(s)}

RRI should be integrated into the operations of the implementing organization(s) by asking "How can RRI be integrated throughout the value chain and design process?" and "Can foresight and ethical and social impact analysis be performed in the context of the existing organizational procedures and practices?”

This step includes at least two interconnected aspects. Firstly, how to translate the co-created and negotiated visions, values and action steps into concrete operations and, secondly, how to integrate responsible ways of acting into the daily routines of the organization.

It has been suggested that RRI evaluation and anticipation should be integrated into existing organizational practices and action models, such as into the existing corporate social responsibility (CSR) functions (Reijers et al., 2018). In this case, the more traditional follow-up of environmental and social impacts of products would be extended with the development phase of products and services.

A challenge here is that in many cases firms do not focus on the innovation process, but rather on product acceptability and impacts (van de Poel et al., 2017). Another challenge may be that CSR is used by companies more as a branding instrument than as an integrated strategic function. Therefore, it has been suggested that a company-specific RRI strategy is needed, which can then be translated into RRI activities and RRI key performance indicators, supporting the uptake of RRI at the whole-company level (ibid.). In addition, RRI could be integrated (as suggested by proponents of lifebased design, e.g. Saariluoma et al., 2016) into the core of the technological design and innovation process. An optimal solution would be for both approaches to be used concurrently.

However, introducing RRI to firms is not an easy task for various reasons. Companies may find RRI discourse difficult or unsuited to them, or may feel that they are already implementing responsibility thinking in various forms 


\section{Mika Nieminen and Veikko Ikonen}

(e.g. user-driven innovation, risk assessment and CSR) (ibid.). Gurzawska and colleagues (2017) have put forward three different categories of incentives that may support the implementation of RRI: external and internal stakeholder incentives, instrumental and non-instrumental incentives, and direct and indirect incentives. Examples include corporate reputation, critical consumerism and RRI certification. In addition, they suggest that employer engagement and good governance may support the implementation of RRI. They also consider RRI-related incentives to be contextual. Factors such as size of company, branch of industry and type of business ecosystem may affect the implementation of RRI. While Gurzawska and his colleagues have studied the general dynamics and environmental stimulants that may support the implementation of RRI, they leave it largely open as to who should implement these incentives and how - whether this should be done by public authorities and/or firms and their associations voluntarily, or whether it is better to just wait for incentives, such as critical consumerism, to emerge. Besides external incentives, much depends on the firms' own selfunderstanding and whether they see RRI as useful. Wider transformation may require the firm to redefine its mission to include, besides economic value creation, also the advancement of social and environmental values (Porter \& Kramer, 2011). In so doing, responsibility thinking would be integrated into the firm's core values and operations.

\subsubsection{Follow-up}

Analysis of the actions of organizations and their social impacts has become increasingly important in our complex and constantly changing societies. As the operational environment is multi-dimensional and includes a temporal dimension with past, current and future developments, we have suggested a multi-method approach based on systematic integration of evaluation and foresight methods to provide a holistic analysis (Nieminen \& Hyytinen, 2015; Hyytinen, 2017).

This holistic approach should include a systemic view of RRI. For instance, an innovation aimed at guaranteeing the personal safety and health of the technology users is likely to be a multi-dimensional phenomenon, making it difficult to isolate the influence of the specific innovation or its attributes. Due to the non-linear, systemic nature of the impacts, the evaluation questions should also be as open as possible. The typical evaluation approach, which is to start with formal targets (such as the above-mentioned safety and health) and then focus throughout the evaluation on the question of whether or not these targets have been achieved, can be blind to even significant unintended outcomes, impacts and side effects. Due to the systemic nature of impacts, the monitoring and follow-up of actions should be based on different data sources (quantitative and qualitative), pay attention to alternative impact paths and unintended consequences and include a multiactor view with various perspectives reflecting different societal values. 
Based on the ideas of developmental evaluation (Patton, 2011), the RRI process should be iterative and lead to learning from experiences and reorientation of activities. Monitoring should be used as a continuous means of steering the RRI activities, with the aim of making them more effective and functional. While we emphasize the significance of developmental evaluation and collective learning, indicators and ex post case studies are needed to make visible what has been achieved. They should be analysed and interpreted in collaboration with the stakeholders and ecosystem actors in order to transform these "snapshots" into collective learning experiences. The achievements, problems and weaknesses should be analysed from various perspectives by engaging the actors in the process. This is important, as assessment of outcomes always includes a number of value- and interestrelated questions.

\subsubsection{Critical questions of the approach}

In order to further develop and validate the model, the premises of the model were discussed in a separately organized international workshop of regional developers of RRI participating in the meeting of the EU-funded MARIE consortium (2017-20210) in Tampere, Finland on 29 May 2018. In total, 20 people from eight European regions participated in the workshop. The group consisted of people with diverse backgrounds dealing with regional developmental activities and supporting the implementation of RRI in their own regions in the context of the MARIE project. MARIE's objective was to improve regional public policy by supporting the dissemination and uptake of RRI among enterprises. Using interregional activities, communication and stakeholder engagement, the partners worked to develop new action plans and strategies for the implementation of RRI. The rationale behind the project was a common experience of challenges related to RRI including, for example, the complexity of the concept and lack of appropriate approaches to implement it in public policies. One of the pilots of the MARIE project was the development of open innovation platforms in one of the 6Aika cities in Finland (Tampere). The MARIE workshop thus created an opportunity for feedback on the RRI evaluation approach and supported the overall goals of MARIE in the implementation of RRI.

The participants of the workshop were unanimous that an evaluation framework for the innovation platforms and for supporting the implementation of RRI is needed, even though this is challenging due to problems related to the attribution of factors producing impacts and a lack of appropriate indicators for measuring impacts. While the developers identified the challenges of a systemic operational environment and the problems it may cause for anticipating and creating impacts, they also hoped that it would be possible to conduct long-lasting system-level evaluation of impacts and related factors. The group was in general agreement that an evaluation framework and standardized criteria for evaluation are needed, as the use 
of evaluation supports the implementation of RRI. Mentioned positive functions of RRI evaluation included, for instance, "to benchmark activities against other open innovation platforms" and "to identify weak points and areas". In addition, participants thought that "management without measurement is dubious" and that evaluation is needed "to improve alignment with societal needs and needs and interests of platform members".

In terms of the suggested evaluation approach, the participants thought that it would make operations and action patterns more visible and under conscious deliberation, which, in turn, would make it possible to learn from the action and develop it further. At the same time, they suggested that, in order to strengthen the approach, the criteria describing responsibility should be integrated in the general follow-up criteria, such as key performance indicators, to create incentives for "doing RRI". The more developmentally oriented evaluation would be conducted as an independent process and the two processes of setting incentives and supporting qualitative development would be separated from each other. This would create more trust towards developmental evaluation, being a major prerequisite for it.

In addition, collaboration and commitment to the shared goals necessitate trust, which can be developed only in a long-running process of working together and in honest, reciprocal dialogue. According to the participants, this makes it possible to develop a shared value base, targets and inclusive evaluation procedures. Thus, while the acknowledgement of different values was considered extremely important in co-creation processes, it was stated that, when the process is not based on trust, it might shrink to mere opinion gathering, without genuine openness, learning and critical reflexivity. Inclusion of various values in the framework of trust would also support a more holistic view of responsibility and a deeper understanding of the co-creation of activities.

Participants also stressed that societal values that facilitate innovation and democratic discussion, such as openness and transparency, capacity building, social diversity and ethics, should be emphasized more in the evaluation. According to the participants, the wider inclusion of values would, in turn, "improve quality of life and help to face a 'black swan', when it happens ${ }^{11}$ " or "to assure that the platform is close to society". For instance, openness and transparency are strongly linked to the operation of platforms - for effective self-organization of actors and coordination of actions it is essential that all actors are visible and identifiable in terms of their capacities, opportunities and roles in the platform. Transparency and clarity of communication convey the values and interpretations of the platform and its functioning.

According to the participants, trust, inclusion and openness support the commitment of actors and the meeting of ideas, which are prerequisites for the development of sustainable and acceptable innovations in a platform. This concerns the whole innovation process, from ideation to marketing and distribution. However, the inclusion of different ideas and values may create sustainable and effective innovations only if these values and ideas for 
future actions, products or services are taken into account in the design and development processes.

The participants considered ensuring the effective and "fair" participation of all relevant stakeholders and actors to be a major challenge in this process. The challenge stretches from the identification of stakeholders and innovation actors to the inclusion of their values and ideas in the design or development process. Who are the stakeholders, and who should be included or left out? If all potential actors are included, is the process any more realistically "doable" and sense making to the actors? Are various perspectives and values sufficiently taken into account? And how should compromises between different perspectives and values be made? These critical questions can only be answered case by case, as the implementation context and developed technologies and services vary, along with the relevant stakeholders and the ways to engage them.

Thus, there are critical questions that need to be kept in mind and solved when the model is applied. Firstly, for motivational and trust-related reasons it might be useful to keep quantitative measurement and incentives separate from the qualitative and developmental evaluation approach. Secondly, in order to be useful the approach should be able to create genuine trust among participants and stakeholders. Otherwise, it would not optimally support the development of positive results. Thirdly, the evaluation process should be as open as possible and include widely different values. A critical issue here is that these different viewpoints must be genuinely taken into account in the process, not only as a legitimizing element to increase the social acceptability of previously made "top-down" decisions. Fourthly, the evaluation should pay careful attention to the identification and engagement of stakeholders to ensure, not only fair and wide, but also effective participation. And finally, the far from simple challenge of functional indicators and their measurement needs to be addressed to provide appropriate follow-up indicators and incentives for RRI. ${ }^{12}$

\subsection{Conclusions}

In this chapter, our premise has been that the development of responsibility in research and innovation depends on complex interactions of various actors, organizational dimensions and their dynamic co-development with the organization's external environment. This is reflected also in systems thinking in evaluation. As our societies and organizations have become increasingly complex and rapidly changing, we should not over-simplify the complexity of impact paths or the heterogeneity of factors and actors contributing to societal impacts. Heterogeneity also emphasizes a diversity of values and interests, which affect the desirability and acceptability of innovations. In addition, as innovation is by definition something that takes place in the future, we need anticipatory approaches to cast light on its social and environmental impacts. 
Following from this, we have suggested an evaluation model that incorporates future orientation, a systemic view and multi-actor approach. The model emphasizes continuous development instead of outcomes. Ideally, the evaluation should be aimed at developing operations and processes from the very beginning, not afterwards. In other words, assessing the acceptability and desirability of an innovation or development takes place in a dialogic process of anticipating the impacts and outcomes of the innovation from the very beginning of the process. In the model, RRI intertwines in a stepwise process with successive innovation and organizational actions. A focal character of the model is co-creation, which helps to define values and operational goals for the innovation activity and supports the assessment of the success of operations. At its best, the process is a loop of continuous learning in which participating organizations and individuals learn from each other during the evaluation process and reflexively develop their activity. The desirability and acceptability of the innovation are supported by creating shared visions for the innovation activity.

However, implementing the model is not without its challenges. For instance, in a complex and systemic environment, the line between an organization and its environment may become blurred and the concept of stakeholder may turn out to be more or less obsolete in describing symbiotic relationships in innovation ecosystems or in global interaction. Neither is balancing between different values and avoidance of value relativism or dominance easy. In addition, not all actors may be motivated to participate in RRI activities. Motivation to participate can, however, be increased by ensuring trust among the participating actors.

As stakeholder and/or citizen participation is the "cornerstone" of our evaluation approach - and of any RRI approach - a specific critical factor for further development of the model is theoretical and practical enquiry into the stakeholder concept. Further studies are needed to clarify its theoretical relevance as well as practical usefulness in implementation situations. Correspondingly, the model as a whole needs to be tested in diverse social contexts and organizations in order to secure sufficient empirical feedback on its elements.

\section{Notes}

1 www.rri-tools.eu/

2 https://cordis.europa.eu/project/rcn/91156/reporting/en

3 https://res-agora.eu/news/

4 www.technopolis-group.com/morri/

5 http://satoriproject.eu/

6 https://6aika.fi/in-english/

7 The companies were asked to describe their current understanding of the responsibility concept in relation to their business. The company personnel were interviewed and the state of the company RRI was defined based on 
these interviews. In a follow-up workshop, the results were discussed and good practices as well as potential issues for improvement were recognized. In addition, intervention activities were proposed in order to increase the companies' RRI maturity.

8 https://6aika.fi/in-english/

9 Source: What is a Stakeholder? Definitions of a Stakeholder: www. stakeholdermap.com/what-is-a-stakeholder.html\#freeman

10 See: www.interregeurope.eu/marie/

11 The speaker is apparently referring to Taleb's (2010) term "black swan" symbolizing an unanticipated or unthinkable occurrence, as well as societal resilience and cohesion during these unexpected developments.

12 For an attempt to develop such indicators for industry, see: Yaghmaei (2018).

\section{References}

Adner, R. (2012) The Wide Lens: A New Strategy for Innovation. London: Portfolio/ Penguin.

Ainasoja, M., Kaasinen, E., Vulli, E., Kulju, M., Reunanen, E., Hautala, R., \& Rytövuori, S. (2012). User involvement in service innovations: Four case studies. In Chesbrough, H. \& Piller, F. (eds.) Bridging Mass Customization \& Open Innovation: Proceedings of the MCPC 2011 Conference. Raleigh, NC: Lulu, p. 40.

Alam, I. (2006). Removing the fuzziness from the fuzzy front-end of service innovations through customer interactions. Industrial Marketing Management, $35,468-480$.

Autio, E. \& Thomas, L. D.W. (2013). Innovation ecosystems. In Dodgson, M., Gann, D.M., \& Phillips, N. (eds.), Oxford Handbook of Innovation Management, Oxford: Oxford University Press. pp. 204-288.

Auvinen, H., Ruutu, S., Tuominen, A., Ahlqvist, T., \& Oksanen, J. (2014). Process supporting strategic decision-making in systemic transitions: Towards emissionfree transport in cities by 2050. Technological Forecasting and Social Change, 94, 97-114.

Borras, S. \& Edler, J. (eds.) (2014). The Governance of Socio-Technical Systems. Explaining Change. Cheltenham, UK: Edward Elgar.

Cabrera, D., Colosi, L., \& Lobdell, C. (2008). Systems thinking. Evaluation and Program Planning, 31, 299-310.

Cao, G., Clarke, S., \& Lehaney, B. (2003). Diversity management in organizational change: Towards a systemic framework. Systems Research, 20, 231-242. doi:10.1002/sres.530

Castells, M. (1996). The Rise of the Network Society. The Information Age: Economy, Society and Culture, Vol. I. Oxford: Blackwell.

Chesbrough, H., Vanhaverbeke, W., \& West, J. (eds.) (2006). Open Innovation: Researching a New Paradigm. Oxford: Oxford University Press.

Damanpour, F. (1996). Organizational complexity and innovation: Developing and testing multiple contingency models. Management Science, 42(5), 693-716. Retrieved from www.jstor.org/stable/2634460

Dyehouse, M., Bennett, D., Harbor, J., Childress, A., \& Dark, M. (2009). A comparison of linear and systems thinking approaches for program evaluation illustrated using Indiana Interdisciplinary GK-12. Evaluation and Program Planning, 32, 187-196. 


\section{8}

Eden, C. \& Ackermann, F. (1998). Making Strategy: The Journey of Strategic Management. London: Sage.

Edquist, C. (2005). Reflections on the systems of innovation approach. Science and Public Policy, 31(6), 485-489.

Eoyang, G. \& Holladay, R. (2013). Adaptive Action, Leveraging Uncertainty in Your Organization. Stanford, CA: Stanford University Press.

Forss, K., Marra, M., \& Schwartz, R. (2011). Evaluating the Complex: Attribution, Contribution, and Beyond. London: Transaction Publishers.

Freeman, R. E. (1984). Strategic Management: A Stakeholder Approach. Boston, MA: Pitman.

Freeman, C. \& Louca, F. (2002). As Time Goes By: From the Industrial Revolutions to the Information Revolution. Oxford: Oxford University Press.

Friedman, M. (2005). The World is Flat. Farrar: Straus and Giroux.

Friedman, B., Kahn, P. H., \& Borning, A. (2006). Value sensitive design and information systems. In Zhang, P. \& Galletta, D. (eds.) Human-Computer Interaction in Management Information Systems: Foundations. New York: M.E. Sharpe, pp. 348-371.

Geels, F. W. \& Schot, J. (2007). Typology of sociotechnical transition pathways. Research Policy, 36, 399-417.

Georghiou, L., Cassingena Harper, J., Keenan, M., Miles, I., \& Popper, R. (eds.) (2008). The Handbook of Technology Foresight. Cheltenham, UK: Edward Elgar.

Gertler, P. J., Martinez, S., Premand, P., Rawlings, L. B., \& Vermeersch, C. M. J. (2011). Impact Evaluation in Practice. Washington, DC: The World Bank.

Gianni, R. (2016). Responsibility and Freedom: The Ethical Realm of RRI. London: John Wiley.

Gurzawska, A., Mäkinen, M., \& Brey, P. (2017). Implementation of Responsible Research and Innovation (RRI) practices in industry: Providing the right incentives. Sustainability, 9 (6) (1036). https://doi.org/10.3390/su9061036

Helbing, D. (2013). Globally networked risks and how to respond. Nature, 497, 51-59.

Holland, J. H. (1995). Hidden Order: How Adaptation Builds Complexity. Reading, MA: Addison-Wesley.

Hughes, T. P. (1983). Networks of Power: Electrification in Western Society, 18801930. Baltimore, MD: Johns Hopkins University Press.

Hyytinen, K. (2017). Supporting Service Innovation via Evaluation: A Future Oriented, Systemic and Multi-actor Approach. Aalto University Publication Series Doctoral Dissertations 14/2017 \& VTT Science 146. Retrieved from: www.vtt.fi/ inf/pdf/science/2017/S146.pdf

João, E., Vanclay, F., \& den Broeder, L. (2011). Emphasising enhancement in all forms of impact assessment: Introduction to a special issue. Impact Assessment and Project Appraisal, 29(3), 170-180. DOI: 10.3152/146155111X12959673 796326

Kaasinen, E., Ainasoja, M., Vulli, E., Paavola, H., Hautala, R., Lehtonen, P., \& Reunanen, E. (2010). User Involvement in Service Innovations. VTT Tiedotteita Valtion Teknillinen Tutkimuskeskus (2552). Espoo, VTT, pp. 1-69.

Kellogg Foundation (2004). Using Logic Models to Bring Together Planning, Evaluation and Action Logic Model Development Guide. Battle Creek, MI: Kellogg Foundation. Retrieved from: www.wkkf.org/Pubs/Tools/Evaluation/ Pub3669.pdf 
Kivisaari, S., Väyrynen, E., \& Saranummi, N. (2004). Knowledge-intensive Service Activities in Health Care Innovation. Case Pirkanmaa. VTT Research Notes 2267. Retrieved from: www.vtt.fi/inf/pdf/tiedotteet/2004/T2267.pdf

Kline, S. J. \& Rosenberg, N. (1986). An overview of innovation. In Landau, R. \& Rosenberg, N. (eds.) The Positive Sum Strategy: Harnessing Technology for Economic Growth. Washington, DC: National Academy Press, pp. 275-305.

Kurzweil, R. (1999). The Age of Spiritual Machines: When Computers Exceed Human Intelligence. New York: Penguin Books.

Lawrence, K. (2013). Developing Leaders in VUCA Environment. Retrieved from: www. growbold.com/2013/developing-leaders-in-a-vuca-environment_UNC.2013.pdf

Leikas, J. (2009). Life-Based Design - A Holistic Approach to Designing HumanTechnology Interaction. VTT Publications 726. Espoo: VTT.

Luppicini, R. (2010). Technoethics and the Evolving Knowledge Society: Ethical Issues in Technological Design, Research, Development, and Innovation. Hershey: IGI Global.

Mayers, J. \& Vermeulen, S. (2005). Stakeholder Influence Mapping. Power Tools. London: International Institute for Environment and Development (IIED).

Mayne, J. (2012). Contribution analysis: Coming of age? Evaluation, 18, 270-280.

Mitchell, R. K., Agle, B. R., \& Wood, D. J. (1997). Toward a theory of stakeholder identification and salience: Defining the principle of who and what really counts. The Academy of Management Review, 22 (4), 853-886.

Moore, J. F. (1996). The Death of Competition: Leadership and Strategy in the Age of Business Ecosystems. New York: HarperBusiness.

MoRRI (2018). Monitoring the Evolution and Benefits of Responsible Research and Innovation. Short Draft Final Report on Insights from Monitoring the Evolution and Benefits of RRI in Europe. European Commission. Retrieved from: www. technopolisgroup.com/wpcontent/uploads/2018/03/D11_MoRRI_Short_Draft_ Final_Report.pdf

Mowles, C. (2014). Complex, but not quite complex enough: The turn to the complexity sciences in evaluation scholarship. Evaluation, 20 (2), 160-175.

Nieminen, M. \& Hyytinen, K. (2015). Future-oriented impact assessment: Supporting strategic decision-making in complex socio-technical environment. Evaluation, 21(4), 448-461.

Ortt, J. R. \& van der Duin, P. A. (2008). The evolution of innovation management towards contextual innovation. European Journal of Innovation Management, 11(4), 522-538, https://doi.org/10.1108/14601060810911147

Owen, R., Bessant, J., \& Heintz, M. (eds.) (2013). Responsible Innovation. Oxford: Wiley.

Patton, M. Q. (2011). Developmental Evaluation: Applying Complexity Concepts to Enhance Innovation and Use. New York, NY: Guilford.

Porter, M. E. \& Kramer, M. R. (January-February 2011). Creating shared value. How to reinvent capitalism and unleash a wave of innovation and growth. Harvard Business Review. Retrieved from: https://hbr.org/2011/01/ the-big-idea-creating-shared-value

Prahalad, C. K. \& Ramaswamy, V. (January-February 2000). Co-opting customer competence. Harvard Business Review. Retrieved from: https://hbr.org/2000/01/ co-opting-customer-competence

Reed, M. S., Graves, A., Dandy, N., Posthumus, H., Hubacek, K., Morris, J., Prell, C., Quinn, C. H., \& Stringer, L. C. (2009). Who's in and why? A typology of 
stakeholder analysis methods for natural resource management. Journal of Environmental Management, 90(5), 1933-1949.

Reijers, W., Brey, P., Jansen, P., Rodrigues, R., Koivisto, R., \& Tuominen, A. (2018). A Common Framework for Ethical Impact Assessment. Stakeholders Acting Together on the Ethical Impact Assessment of Research and Innovation. SATORI. D4.1. Retrieved from: http://satoriproject.eu/media/D4.1_Annex_1_ EIA_Proposal.pdf

Responsible-Industry Project Consortium (2017). Guide for the Implementation of Responsible Research and Innovation (RRI) in the Industrial Context. Responsible Industry. Retrieved from: www.responsible-industry.eu/

Rittel, H. \& Webber, M. (1973). Dilemmas in a general theory of planning. Policy Sciences, 4, 155-169.

Rotmans, J. \& Loorbach, D. (2009). Complexity and transition management. Journal of Industrial Ecology, 13(2), 184-196.

Saariluoma, P., Cañas, J. J., \& Leikas, J. (2016). Designing for Life - A Human Perspective on Technology Development. London: Palgrave MacMillan.

Sanders, E. B. \& Stappers, P. (2008). Co-creation and the new landscapes of design. CoDesign, 4(1), 5-18.

Schot, J. \& Rip, A. (1997). The past and future of constructive technology assessment. Technological Forecasting and Social Change, 54, 251-268.

Schot, W. J. \& Steinmueller, E. (2018). Three frames for innovation policy: R\&D, systems of innovation and transformative change. Research Policy, 47(9), 1554-1567.

Simon, J. (2016). Value-sensitive design and responsible research and innovation. In Hansson, S. O. (ed.) The Ethics of Technology - Methods and Approaches. London: Rowman \& Littlefield, pp. 219-236.

Smallman, M. (2018). Citizen science and Responsible Research and Innovation. In Bonn, A., Haklay, M., Hecker, S., Bowser, A., Makuch, Z. \& Vogel, J. (eds.) Citizen Science - Innovation in Open Science, Society and Policy. London: UCL Press, pp. 241-253.

Smith, K. R. (2000). Innovation as a systemic phenomenon: Rethinking the role of policy. Enterprise and Innovation Management Studies, 1(1), 73-102.

Stahl, B. C., Obach, M., Yaghmaei, E., Ikonen, V., Chatfield, K., \& Brem, A. (2017). The Responsible Research and Innovation (RRI) maturity model: Linking theory and practice. Sustainability, 9,1036.

Stilgoe, J., Owen, R., \& Macnaghten, P. (2013). Developing a framework for responsible innovation. Research Policy, 42(9), 1568-1580.

Sutcliffe, H. (2011). A Report on Responsible Research and Innovation. Retrieved from: https://ec.europa.eu/research/science-society/document_library/pdf_06/rrireport-hilary-sutcliffe_en.pdf

Taleb, N. N. (2010) The Black Swan. The Impact of the Highly Improbable. Revised edition. London: Penguin.

Teece, D. (1988). Technological change and the nature of the firm. In Dosi, G., Freeman, C., Nelson, R., Silverberg, G. \& Soete, L. (eds.) Technical Change and Economic Theory. London: Pinter Publishers, pp. 256-281.

Tsoukas, H. \& Chia, R. (2002). On organizational becoming: Rethinking organizational change. Organization Science, 13(5), 567-582.

Urry, J. (2005). The complexity turn. Theory, Culture and Society, 22(5), 1-14. 
van de Poel, I., Asveld, L., Flipse, S., Klaassen, P., Scholten, V., \& Yaghmaei, E. (2017). Company strategies for Responsible Research and Innovation (RRI): A conceptual model. Sustainability, 9(11), 2045.

van Wezel, A. P., van Lente, H., van de Sandt, J. J., Bouwmeester, H., Vandeberg, R. L., \& Sips, A. J. (2018). Risk analysis and technology assessment in support of technology development: Putting responsible innovation in practice in a case study for nanotechnology. Integrated Environmental Assessment and Management, 14,916. doi:10.1002/ieam.1989

von Hippel, E. (1988). The Sources of Innovation. New York: Oxford University Press. von Schomberg, R. (2011). Towards Responsible Research and Innovation in the Information and Communication Technologies and Security Technologies Fields. A Report from the European Commission Services. Belgium: European Commission.

Wholey, J. S., Hatry, H. P., \& Newcomer, K. E. (eds.) (2010). Handbook of Practical Program Evaluation. Third Edition. San Francisco, CA: Jossey-Bass.

Williams, B. \& Hummelbrunner, R. (2011). Systems Concepts in Action. A Practitioner's Toolkit. Stanford, CA: Stanford University Press.

Williams, B. \& Imam, I. (eds.) (2006). Systems Concepts in Evaluation: An Expert Anthology. Point Reyes, CA: EdgePress of Inverness.

Yaghmaei, E. (2018). Responsible research and innovation key performance indicators in industry: A case study in the ICT domain. Journal of Information, Communication and Ethics in Society, 16(2), 214-234. https://doi.org/10.1108/ JICES-11-2017-0066 